\title{
Physicians with disabilities often undervalued
}

\author{
Cite as: CMAJ 2017 May 8;189:E678-9. doi: 10.1503/cmaj.1095402
}

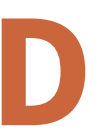
r. Jessica Dunkley is currently completing her residency in dermatology at the University of British Columbia. Like most doctors-in-training in this country, she completed her undergraduate medical degree and hoped to pursue a specialty. Unlike most doctors in training, Dunkley's path to her chosen profession also required going to the BC Human Rights Tribunal and the Supreme Court of British Columbia.

Dunkley is deaf. Indeed, she is one of the first deaf doctors in the country and the first hearing-impaired Métis doctor to practise in Canada. After being accepted into the dermatology program at UBC and St. Paul's Hospital in 2010, the new medical graduate was informed that her request for sign language interpreters could not be accommodated. In 2011, she was dismissed from the residency program by UBC and dismissed as an employee by Providence Health Care, which operates St. Paul's.

Five years later, the human rights commission ruled the dismissal was discriminatory. Another year would pass before the Supreme Court of British Columbia handed down its decision, also in Dunkley's favour.

Dunkley's trials and tribulations reflect a lack of awareness and discomfort with physicians with disabilities. That is particularly true for individuals looking to begin their medical career, says Dunkley. "People are not receptive of individuals who enter medical school with a pre-existing medical condition. However, if you have already proven yourself as an able-bodied person, they are already aware of what you could do."

Dr. Vera Krejcik, president of the Canadian Association of Physicians with Disabilities, notes that, "There is a much lower percentage of physicians with disabilities than in the Canadian population as a whole."
While comprehensive data are difficult to come by, Statistics Canada reports that in 2011, there were about 9000 working Canadian physicians with disabilities. That's $11.2 \%$ of the total, compared with $13.7 \%$ of Canadians overall who self-identified as disabled in 2012.

New research published December 2016 in JAMA assessed the prevalence of disabilities among medical students and the accommodations in use at medical

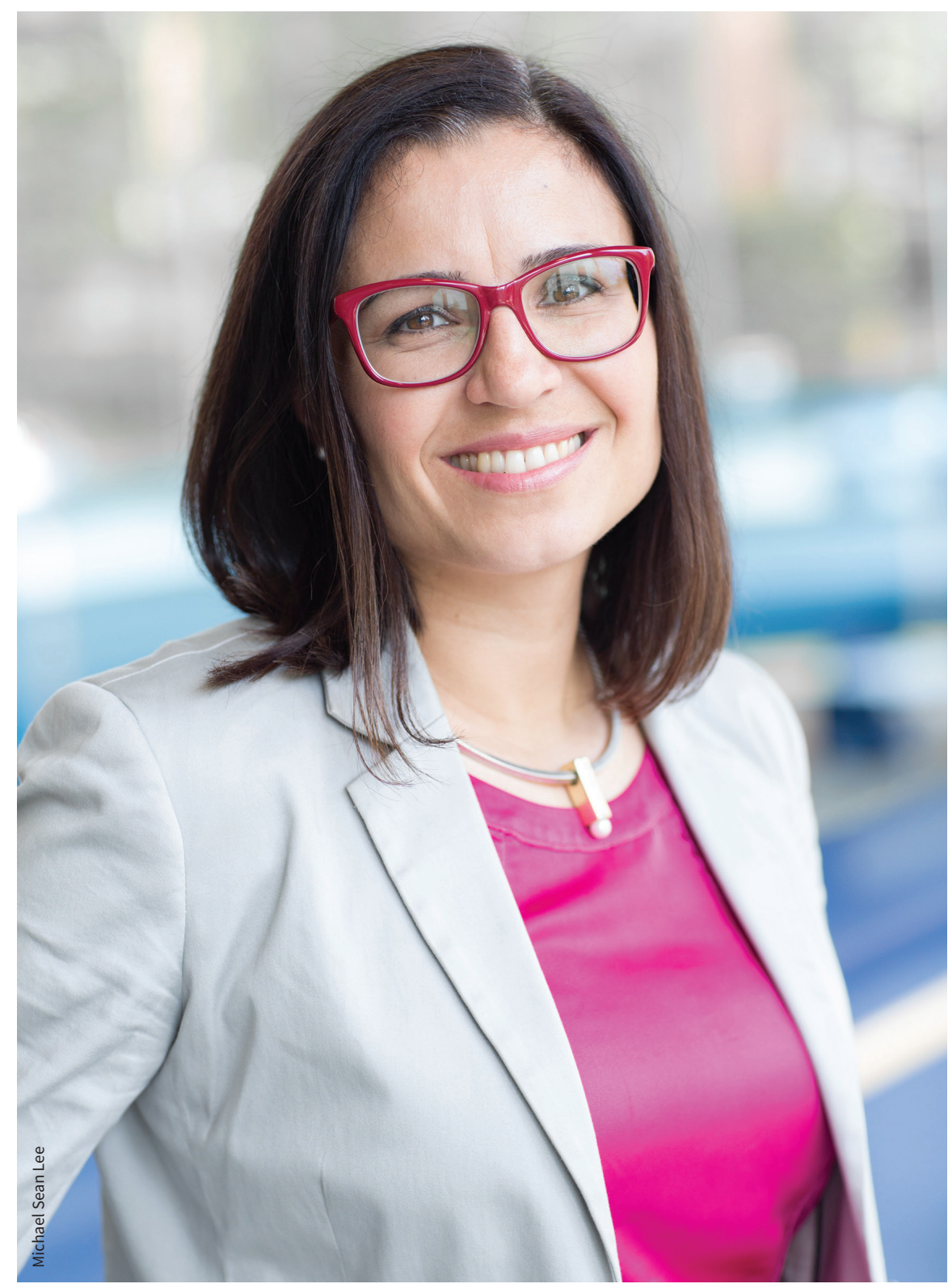

According to Dr. Jessica Dunkley, who is deaf, medical administrators are often reluctant to work with doctors who have disabilities. 
schools in the United States. The authors noted that, "It remains unclear how many medical students have disabilities; prior estimates are out-of-date and psychological, learning, and chronic health disabilities have not been evaluated."

The 91 schools that responded (68\% of the total) identified 1547 students with disabilities, representing $2.7 \%$ of the total enrollment (previous studies showed a prevalence of $0.3 \%$ to $0.6 \%$ ). Of these students, $97.7 \%$ received accommodations for their disability. The study found that the most common disability was attentiondeficit/hyperactivity disorder (33.7\%), followed by learning disabilities $(21.5 \%)$ and psychological disabilities (20\%).

Dunkley, a recipient of the "Extraordinary Woman" award at the University of Ottawa, says that in her experience, the reluctance to work with a disabled physician did not come primarily from colleagues, but from administration and others not on the frontlines of medicine. "They anticipate issues or consequences without evidence," she says. "It really comes down to having an open conversation with the individuals and asking them what works and what needs to happen."

Such conversations are becoming more commonplace, but there is often still much uncertainty and unwillingness. Acceptance, notes Krejcik, "is a nuanced and challenging road."

The law requires accommodation for individuals with disabilities up to the point of undue hardship, which can be a legal grey area. (Both UBC and Providence Health Care argued undue hardship, specifically the cost of interpreters.)

speed and efficiency are integral to the process, says Krejcik. "The accommodation process is almost glacial."

Ultimately the issue goes beyond finances and efficiency. In the BC Human Rights Tribunal's written decision, Marlene Tyshynski spoke to the "profound impact" the lack of support had on Dunkley. "The discrimination entirely undermined her optimism, brilliance and efforts.... She felt dehumanized and devalued."

Greater diversity is occurring within the medical profession Dunkley believes, in large part thanks to a more open and receptive younger generation of physicians. Seeing physicians with disabilities in practice is also changing perceptions and promoting greater acceptance, she notes. "Most people have never encountered a physician who is deaf."

donalee Moulton, Halifax, Nova Scotia 